\title{
Systemic and microcirculatory effects of blood transfusion in experimental hemorrhagic shock
}

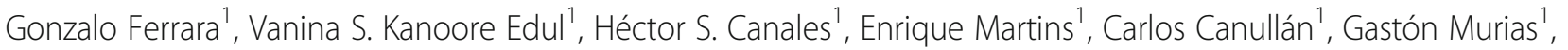
Mario O. Pozo ${ }^{1}$, Juan F. Caminos Eguillor ${ }^{1}$, María G. Buscetti ${ }^{1}$, Can Ince ${ }^{2}$ and Arnaldo Dubin ${ }^{1 *}$

\author{
* Correspondence: \\ arnaldodubin@gmail.com \\ ${ }^{1}$ Cátedra de Farmacología Aplicada, \\ Facultad de Ciencias Médicas, \\ Universidad Nacional de La Plata, La \\ Plata, Argentina \\ Full list of author information is \\ available at the end of the article
}

\begin{abstract}
Background: The microvascular reperfusion injury after retransfusion has not been completely characterized. Specifically, the question of heterogeneity among different microvascular beds needs to be addressed. In addition, the identification of anaerobic metabolism is elusive. The venoarterial $\mathrm{PCO}_{2}$ to arteriovenous oxygen content difference ratio $\left(\mathrm{P}_{\mathrm{v}-\mathrm{a}} \mathrm{CO}_{2} / \mathrm{C}_{\mathrm{a}-\mathrm{v}} \mathrm{O}_{2}\right)$ might be a surrogate for respiratory quotient, but this has not been validated. Therefore, our goal was to characterize sublingual and intestinal (mucosal and serosal) microvascular injury after blood resuscitation in hemorrhagic shock and its relation with $\mathrm{O}_{2}$ and $\mathrm{CO}_{2}$ metabolism.
\end{abstract}

Methods: Anesthetized and mechanically ventilated sheep were assigned to stepwise bleeding and blood retransfusion $(n=10)$ and sham $(n=7)$ groups. We performed analysis of expired gases, arterial and mixed venous blood gases, and intestinal and sublingual videomicroscopy.

Results: In the bleeding group during the last step of hemorrhage, and compared to the sham group, there were decreases in oxygen consumption (3.7 [2.8-4.6] vs. 6.8 [5. 8-8.0] $\left.\mathrm{mL} \mathrm{min}^{-1} \mathrm{~kg}^{-1}, P<0.001\right)$ and increases in respiratory quotient $(0.96$ [0.91-1.06] vs. 0.72 [0.69-0.77], $P<0.001$ ). Retransfusion normalized these variables. The $\mathrm{P}_{\mathrm{v}-\mathrm{a}} \mathrm{CO}_{2} / \mathrm{C}_{\mathrm{a}-\mathrm{a}}$ ${ }_{v} \mathrm{O}_{2}$ increased in the last step of bleeding (2.4 [2.0-2.8] vs. $\left.1.1[1.0-1.3], P<0.001\right)$ and remained elevated after retransfusion, compared to the sham group (1.8 [1.5-2.0] vs. 1.1 [0.9-1.3], $P<0.001)$. $\mathrm{P}_{\mathrm{v}-\mathrm{a}} \mathrm{CO}_{2} / \mathrm{C}_{\mathrm{a}-\mathrm{v}} \mathrm{O}_{2}$ had a weak correlation with respiratory quotient (Spearman $R=0.42, P<0.001$ ). All the intestinal and sublingual microcirculatory variables were affected during hemorrhage and improved after retransfusion. The recovery was only complete for intestinal red blood cell velocity and sublingual total and perfused vascular densities.

Conclusions: Although there were some minor differences, intestinal and sublingual microcirculation behaved similarly. Therefore, sublingual mucosa might be an adequate window to track intestinal microvascular reperfusion injury. Additionally, $\mathrm{P}_{\mathrm{v}-\mathrm{a}} \mathrm{CO}_{2} / \mathrm{C}_{\mathrm{a}-\mathrm{v}} \mathrm{O}_{2}$ was poorly correlated with respiratory quotient, and its physiologic behavior was different. Thus, it might be a misleading surrogate for anaerobic metabolism.

Keywords: Hemorrhage, Shock, Transfusion, Microcirculation, Hypoxia 


\section{Background}

Hemorrhagic shock is a major cause of morbidity and mortality after trauma and other conditions. The restoration of systemic oxygen transport may not prevent the development of multiple organ failure. Possible explanations for this phenomenon are the oxygen debt accumulated during shock [1], the reperfusion injury mainly related to oxygen species production [2], and the persistent depression of microvascular perfusion [3]. Although the microcirculation in experimental hemorrhagic shock has been extensively described [4, 5], the microcirculatory alterations after blood resuscitation have not been completely studied. Specifically, the issue of perfusion heterogeneity among different microvascular beds needs to be adequately addressed.

The identification of anaerobic metabolism after the normalization of systemic hemodynamics in shock states is elusive. Even though several systemic variables may track the presence of tissue hypoxia, none of them is specific or sensitive. The acute increase in respiratory quotient $(\mathrm{RQ})$ is an excellent marker of ongoing anaerobic metabolism in both exercise and oxygen supply dependency [6-8]. In both circumstances, there is an excess of $\mathrm{CO}_{2}$ production $\left(\mathrm{VCO}_{2}\right)$ compared to oxygen consumption $\left(\mathrm{VO}_{2}\right)$, which results from anaerobic $\mathrm{VCO}_{2}$. This arises from bicarbonate buffering of anaerobically generated protons (i.e., lactic acid dissociation, ATP hydrolysis). The measurement of $\mathrm{RQ}$, however, requires analysis of expired gases by means of a metabolic cart. Such monitoring is usually not available in the ICU. Recently, observational studies found that venoarterial $\mathrm{PCO}_{2}$ difference $\left(\mathrm{P}_{\mathrm{v}-\mathrm{a}} \mathrm{CO}_{2}\right)$ to arteriovenous oxygen content difference $\left(\mathrm{C}_{\mathrm{a}-\mathrm{v}} \mathrm{O}_{2}\right)$ ratio might be a surrogate for RQ $[9,10]$. This assumption relies on Fick's principle, which states that $\mathrm{VCO}_{2}$ and $\mathrm{VO}_{2}$ can be calculated as the product of cardiac output by the respective venoarterial content difference. This also assumes a linear relationship between $\mathrm{CO}_{2}$ content and pressure. Nevertheless, those studies have not compared $\mathrm{P}_{\mathrm{v}-\mathrm{a}} \mathrm{CO}_{2} / \mathrm{C}_{\mathrm{a}-\mathrm{v}} \mathrm{O}_{2}$ with $\mathrm{RQ}$.

Our goal was to characterize the intestinal mucosal and serosal microvascular alterations during hemorrhagic shock and retransfusion (H/R) and its relation with $\mathrm{O}_{2}$ and $\mathrm{CO}_{2}$ metabolism. A secondary objective was to correlate gut abnormalities with those of sublingual mucosa, a more accessible window in critically ill patients. Our hypotheses were (1) intestinal mucosal microcirculation is more susceptible than the other territories and (2) $\mathrm{P}_{\mathrm{v}-\mathrm{a}} \mathrm{CO}_{2} / \mathrm{C}_{\mathrm{a}-\mathrm{v}} \mathrm{O}_{2}$ fails to reflect the changes in RQ.

\section{Methods}

\section{Anesthesia and ventilation}

Seventeen sheep $\left(23 \pm 7 \mathrm{~kg}\right.$, mean $\pm \mathrm{SD}$ ) were anesthetized with $30 \mathrm{mg} \mathrm{kg}^{-1}$ of sodium pentobarbital and intubated and mechanically ventilated with a Servo Ventilator 900C (Siemens-Elema AB, Solna, Sweden) with a tidal volume of $15 \mathrm{~mL} \mathrm{~kg}^{-1}$, a $\mathrm{FiO}_{2}$ of 0.21 , and a positive end-expiratory pressure of $6 \mathrm{cmH}_{2} \mathrm{O}$. The initial respiratory rate was set to keep the arterial $\mathrm{PCO}_{2}$ between 35 and $40 \mathrm{mmHg}$. This respiratory setting was maintained during the rest of the experiment. Neuromuscular blockade was performed with pancuronium bromide $\left(0.06 \mathrm{mg} \mathrm{kg}^{-1}\right)$. Additional pentobarbital boluses $\left(1 \mathrm{mg} \mathrm{kg}{ }^{-1}\right)$ were administered hourly and when clinical signs of inadequate depth of anesthesia were 
evident. Analgesia was provided by fentanyl as a bolus of $2 \mu \mathrm{g} \mathrm{kg}{ }^{-1}$, followed by $1 \mu \mathrm{g} \mathrm{h}$

${ }^{-1} \mathrm{~kg}^{-1}$. These drugs were administered intravenously.

\section{Surgical preparation}

A 7.5-French Swan-Ganz Standard Thermodilution Pulmonary Artery Catheter (Edwards Life Sciences, Irvine, CA, USA) was inserted through an introducer in the right external jugular vein to obtain mixed venous samples; its side port was used to administer fluids and drugs. Catheters were placed in the descending aorta via the left femoral artery to measure blood pressure, perform the bleeding, and obtain blood samples, and in the inferior vena cava to perform the retransfusion.

A midline laparotomy was performed, followed by a gastrostomy to drain gastric contents, and a splenectomy to avoid spleen contraction during the hemorrhage. An electromagnetic flow probe was placed around the superior mesenteric artery to measure blood flow (SMABF). A catheter was introduced in the mesenteric vein through a small vein proximal to the gut to draw blood samples and to measure pressure. A tonometer was inserted through a small ileotomy to measure intramucosal $\mathrm{PCO}_{2}$. A 10 - to $15-\mathrm{cm}$ segment of the ileum was mobilized, placed outside the abdomen, and opened $2 \mathrm{~cm}$ on the antimesenteric border to allow an examination of mucosal microcirculation. The exteriorized intestinal segment was covered and moisture and temperature preserved by a device. Finally, after complete hemostasis, the abdominal-wall incision was closed, excepting a short segment for externalization of the ileal loop.

\section{Measurements and derived calculations}

Systemic $\mathrm{VO}_{2}, \mathrm{VCO}_{2}$, and $\mathrm{RQ}$ were measured by analysis of expired gases (MedGraphics CPX Ultima, Medical Graphics Corporation, St. Paul, $\mathrm{MN}) . \mathrm{VO}_{2}$ and $\mathrm{VCO}_{2}$ were adjusted to body weight.

Arterial, mixed venous, and mesenteric venous $\mathrm{PO}_{2}, \mathrm{PCO}_{2}, \mathrm{pH}, \mathrm{Hb}$, and $\mathrm{O}_{2}$ saturation were measured with a blood gas analyzer and a co-oximeter (ABL 5 and OSM 3, Radiometer, Copenhagen, Denmark). Oxygen-derived variables were calculated by standard formulae. Systemic and intestinal $\mathrm{C}_{\mathrm{a}-\mathrm{v}} \mathrm{O}_{2}$ were calculated using mixed and mesenteric venous $\mathrm{O}_{2}$ saturation and $\mathrm{P}_{\mathrm{v}-\mathrm{a}} \mathrm{CO}_{2} / \mathrm{C}_{\mathrm{a}-\mathrm{v}} \mathrm{O}_{2}$ by means of mixed venous blood.

Cardiac index $(\mathrm{CI})$ was calculated as $\mathrm{VO}_{2}$ divided by systemic $\mathrm{C}_{\mathrm{a}-\mathrm{v}} \mathrm{O}_{2}$. Systemic oxygen transport $\left(\mathrm{DO}_{2}\right)$ was calculated as $\mathrm{CI}$ by arterial $\mathrm{O}_{2}$ content.

SMABF was measured by the electromagnetic method (Spectramed Blood Flowmeter model SP 2202 B, Spectramed Inc., Oxnard, CA, USA), with in vitro calibrated transducers of 5-7 mm diameter (Blood Flowmeter Transducer, Spectramed Inc., Oxnard, CA, USA). Occlusive zero was controlled before and after each experiment. Nonocclusive zero was corrected before each measurement. SMABF was referred to gut weight. Intestinal $\mathrm{DO}_{2}$ was calculated as $\mathrm{SMABF}$ by arterial $\mathrm{O}_{2}$ content and intestinal $\mathrm{VO}_{2}$ as SMABF by intestinal $\mathrm{C}_{\mathrm{a}-\mathrm{v}} \mathrm{O}_{2}$.

Intramucosal $\mathrm{PCO}_{2}$ was measured by air tonometry (Tonometrics Catheter and Tonocap, Datex-Ohmeda, Helsinki, Finland). Then, we calculated intramucosal-arterial $\mathrm{PCO}_{2}\left(\triangle \mathrm{PCO}_{2}\right)$.

Arterial lactate was measured with a point-of-care analyzer (Stat Profile Critical Care Xpress, Nova Biomedical, Waltham, MA, USA). 


\section{Microvideoscopic measurements and analysis}

The microcirculatory network was evaluated in intestinal mucosa and serosa, and sublingual mucosa by means of a sidestream-dark-field (SDF) imaging device (Microscan, MicroVision Medical, Amsterdam, Netherlands) [11]. Different precautions were taken and steps followed to obtain images of adequate quality and to insure satisfactory reproducibility. After gentle removal of saliva by isotonic-saline-drenched gauze, steady images of at least $20 \mathrm{~s}$ were obtained while avoiding pressure artifacts with a portable computer and an analog-to-digital video converter (ADVC110, Canopus Co., San Jose, CA, USA). The videos were recorded from three different areas. Video clips were stored as AVI files to allow computerized frame-by-frame image analysis.

Video-image analysis was performed blindly by well-trained researchers. Adequate focus and contrast adjustment were verified, and images of poor quality were discarded. The entire sequence was used to describe the semiquantitative characteristics of the microvascular flow and, particularly, the presence of stopped or intermittent flow.

We used an image-analysis software (Microscan analysis software-AVA 3.0-MicroVision Medical, Amsterdam, Netherlands) [12] to determine total vascular density. An analysis based on semiquantitative criteria that distinguished no flow (0), intermittent flow [1], sluggish flow [2], and continuous flow [3] was performed on individual vessels [3]. The overall score, called microvascular flow index (MFI), is the average of the individual values [13]. Quantitative red blood cell (RBC) velocity was determined using space-time diagrams [12]. We also calculated the proportion of perfused vessels, the perfused vascular density (i.e., the total vascular density multiplied by the fraction of perfused vessels), and the heterogeneity flow index as highest-lowest MFI divided mean MFI [14].

In sheep, most of sublingual vascular density $(97 \pm 1 \%)$ and all intestinal vessels consist of small vessels (diameter $<25 \mu \mathrm{m}$ ) [5], so analysis was focused on these types of vessels, whereas the vessels of higher diameter were assessed only for ruling out compression artifacts.

\section{Experimental procedure}

Basal measurements were taken after a period of no less than $30 \mathrm{~min}$ after systemic $\mathrm{VO}_{2}, \mathrm{VCO}_{2}$, and SMABF became stable. Animals were then assigned to $\mathrm{H} / \mathrm{R}(n=10)$ or sham $(n=7)$ group. In the $\mathrm{H} / \mathrm{R}$ group, three consecutive bleedings of $5-10 \mathrm{~mL} \mathrm{~kg}$ were performed at 30-min intervals, until reaching reductions in systemic $\mathrm{VO}_{2}$ and increases in RQ. Then, shed blood was rapidly reinfused $(\sim 2 \mathrm{~min})$ and sheep were followed during one additional hour. In the sham group, the same experimental preparation was carried out and $0.9 \% \mathrm{NaCl}$ was infused to maintain hemodynamic variables at basal values, without further interventions. Measurements were performed at baseline $\left(0^{\prime}\right)$, during bleeding $\left(30^{\prime}, 60^{\prime}\right.$, and $\left.90^{\prime}\right)$, and after retransfusion $\left(2^{\prime}, 30^{\prime}\right.$, and $\left.60^{\prime}\right)$. Microcirculatory videos were only acquired at $0^{\prime}, 30^{\prime}$, and 90' of hemorrhage and 60' of retransfusion, but in sublingual mucosa, images were also continuously obtained during blood reinfusion. Thereafter, the initial and the final portion of these videos $\left(0^{\prime}\right.$ and $\left.2^{\prime}\right)$ were analyzed. Blood temperature was kept constant throughout the study with a heating lamp.

At the end of the experiment, animals were killed with an additional dose of pentobarbital and a $\mathrm{KCl}$ bolus. A catheter was inserted in the superior mesenteric artery, and 
Indian ink was instilled through it. Dyed intestinal segments were dissected, washed, and weighed to calculate gut indexes.

\section{Data analysis}

Because of the small numbers of animals, nonparametric tests were used. Changes over time within each group were assessed with nonparametric analysis of variance for repeated measurements (Friedman test) followed by a post hoc test (Dunn's multiple comparison test). Differences between groups at each time point were analyzed with Mann-Whitney $U$ test. Correlations between variables were calculated with Spearman test. Data are expressed as median and interquartile range. A $P$ value $<0.05$ was considered statistically significant.

\section{Results}

\section{Effects on systemic and intestinal hemodynamics and oxygen transport}

In the $H / R$ group, mean arterial pressure decreased from the first step of bleeding, while reductions in $\mathrm{CI}$ and SMABF reached statistical significance during the last stage (Table 1). Each variable was normalized after retransfusion, but at 2', CI and SMABF were higher than baseline. During bleeding, there were progressive reductions in systemic and intestinal $\mathrm{DO}_{2}$ which, in the last step, were associated with systemic and intestinal $\mathrm{VO}_{2}$ falls and RQ increases (Figs. 1 and 2). During retransfusion, all these variables were normalized. Bleeding induced lactic acidosis, which persisted after retransfusion (Fig. 3).

\section{Effects on $\mathrm{CO}_{2}$ metabolism}

Compared to baseline, $\mathrm{VCO}_{2}$ decreased in the last step of bleeding and increased at 2' of retransfusion. Systemic and intestinal $\mathrm{P}_{\mathrm{v}-\mathrm{a}} \mathrm{CO}_{2}$ and $\triangle \mathrm{PCO}_{2}$ augmented during bleeding and were normalized during retransfusion (Fig. 2 and Table 2). $\triangle \mathrm{PCO}_{2}$ correlated with intestinal mucosal total vascular density $(R=-0.44, P=0.0002)$, perfused vascular density $(R=-0.43, P=0.0003)$, proportion of perfused vessels $(R=-0.48, P<0.0001)$, RBC velocity $(R=-0.35, P<0.001)$, MFI $(R=-0.52, P<0.0001)$, and heterogeneity flow index $(R=0.52, P<0.0001)$.

$\mathrm{P}_{\mathrm{v}-\mathrm{a}} \mathrm{CO}_{2} / \mathrm{C}_{\mathrm{a}-\mathrm{v}} \mathrm{O}_{2}$ increased during bleeding and, during retransfusion, remained higher than that of the sham group. This ratio correlated with $\mathrm{RQ}(R=0.42, P<0.0001)$ (Fig. 2).

\section{Effects on microcirculation}

From the first step of bleeding, each intestinal and sublingual microcirculatory variable was compromised.

During retransfusion, all the variables improved in the three territories. However, proportion of perfused vessels, microvascular flow index, and heterogeneity flow index could not be normalized. RBC velocity returned to basal values in intestinal mucosa and serosa and persisted diminished in sublingual mucosa. Conversely, total and perfused vascular density remained low in intestinal mucosa and serosa and were restored to baseline in sublingual mucosa.

In sublingual mucosa, each microvascular variable improved after 2 ' of blood reinfusion. Such variables were similar at $2^{\prime}$ and $60^{\prime}$ of retransfusion (Figs. 4, 5, and 6 and the video in Additional file 1). 


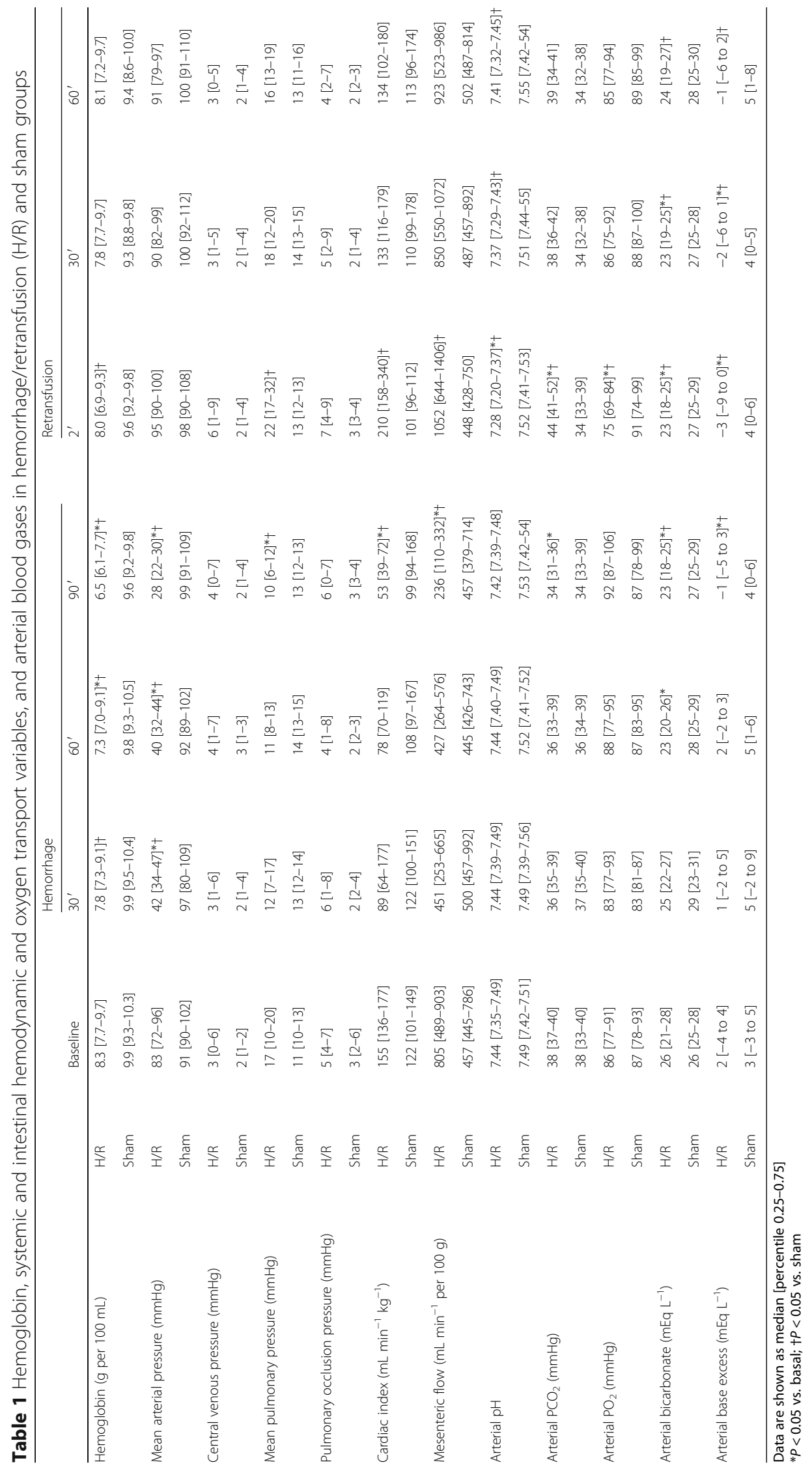



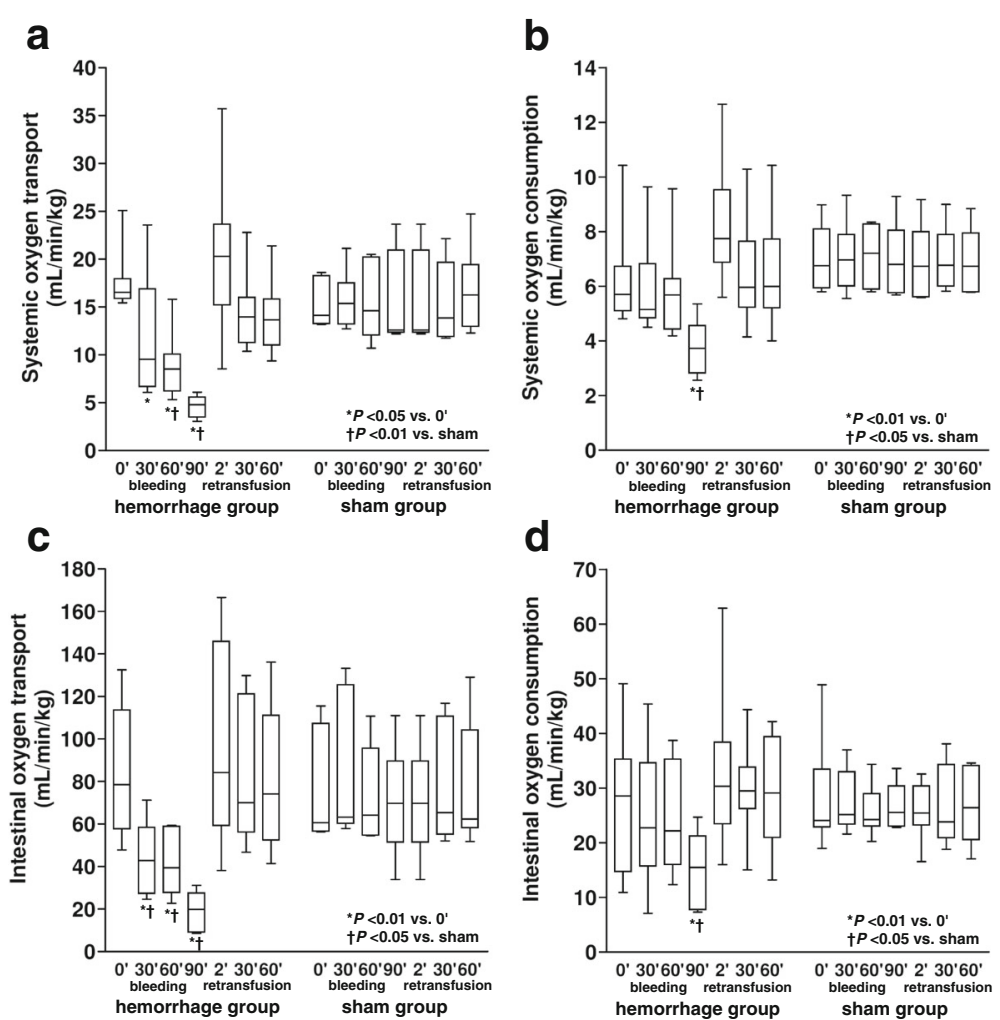

Fig. 1 Behavior of systemic and intestinal $\mathrm{O}_{2}$ transport and consumption. a Systemic $\mathrm{O}_{2}$ transport. b Systemic $\mathrm{O}_{2}$ consumption. c Intestinal $\mathrm{O}_{2}$ transport. d Intestinal $\mathrm{O}_{2}$ consumption

\section{Discussion}

Our main finding was that retransfusion improved the microcirculatory alterations that developed in hemorrhagic shock. However, subtle abnormalities persisted in the face of the normalization of aerobic metabolism. Microvascular reperfusion injury was present in the three studied vascular beds, with minor differences among them. In addition, $\mathrm{P}_{\mathrm{v}-\mathrm{a}} \mathrm{CO}_{2} / \mathrm{C}_{\mathrm{a}-\mathrm{v}} \mathrm{O}_{2}$ only showed a weak correlation with RQ and, mainly, remained elevated during retransfusion.

In experimental hemorrhagic shock, the reports of the microcirculatory effects of blood transfusion are controversial. For example, in rats, transfusion deteriorated

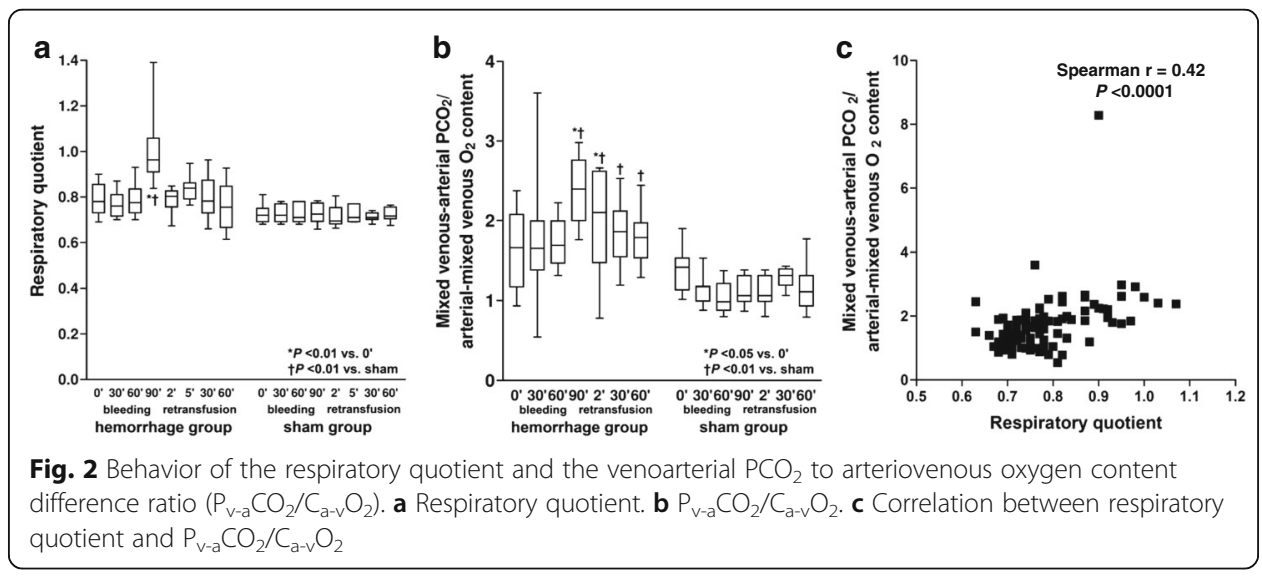



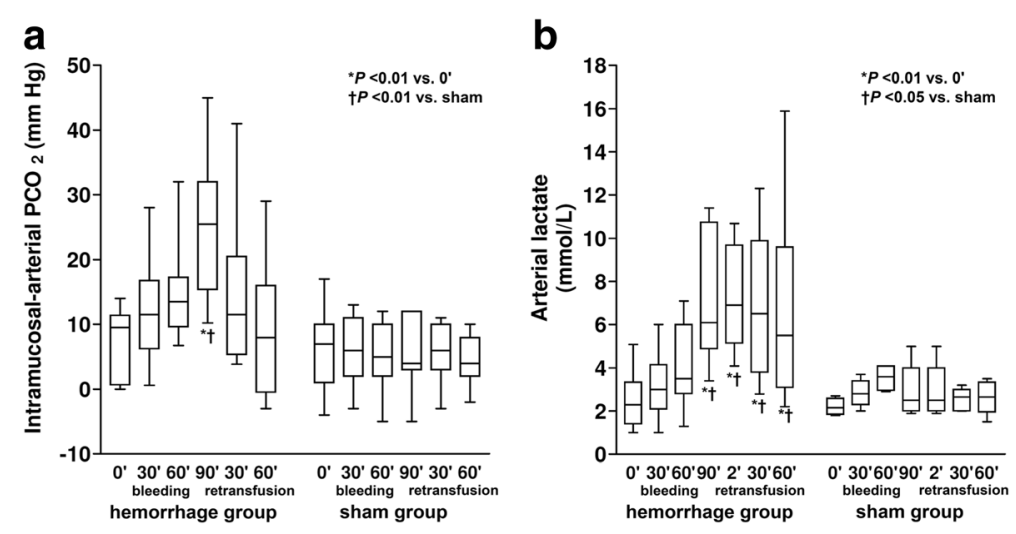

Fig. 3 Behavior of intramucosal-arterial $\mathrm{PCO}_{2}$ difference and arterial lactate. a Intramucosal-arterial $\mathrm{PCO}_{2}$ difference. b Arterial lactate

perfused capillary density of gastric mucosa [15]. Conversely, in another study, RBC administration restored conjunctival microcirculation and muscle tissue oxygenation [16]. In the hamster window chamber model, packed fresh RBC improved but not completely normalized functional capillary density and flow [17, 18]. Partial beneficial effects were also found on rat hepatic and ileum microcirculation [19, 20].

These inconsistent results might be related to differences in the studied species, in the severity of shock, and in the particular microvascular bed evaluated. Accordingly, it has been suggested that the gut might be less responsive to blood resuscitation than the heart [21]. We found beneficial effects of blood resuscitation on intestinal and sublingual microcirculation. The recovery of microvascular perfusion, however, was incomplete, and regional deficits persisted. The novelty of our study consists in the assessment of different and relevant microvascular beds, along with a comprehensive evaluation of systemic and regional hemodynamics and oxygenation.

Microcirculatory reperfusion injury exhibited different manifestations in sublingual and intestinal territories. Although in the three areas blood reinfusion improved all the microvascular variables, only sublingual densities and intestinal RBC velocity were completely normalized. Taking into account these minor regional differences, the sublingual mucosa might be an adequate window for the monitoring of reperfusion microvascular injury. This situation might differ in other forms of distributive shock. After the resuscitation of septic shock, microcirculatory derangements are more severe in intestinal than in sublingual mucosa [22-24]. In a sheep model of endotoxic shock, the hemodynamic normalization by means of fluids corrected sublingual microcirculation whereas intestinal villi remained hypoperfused [22]. The reasons for this higher heterogeneity between microvascular beds in sepsis than in our model reperfusion injury are uncertain but might be related to different mechanisms of damage as well as the modality of resuscitation (colloid or crystalloid solutions vs. blood).

The subtle villi abnormalities could trigger mechanisms of tissue damage such as the alteration in the mucosa barrier dysfunction and systemic translocation of bacteria and their products [25]. What is more, in patients with traumatic hemorrhagic shock, the persistence of microcirculatory alterations after resuscitation predicted the development of multiorgan failure [26]. The microcirculatory dysfunction has also been proposed as the link between trauma and coagulopathy [27]. In addition, the presence of 


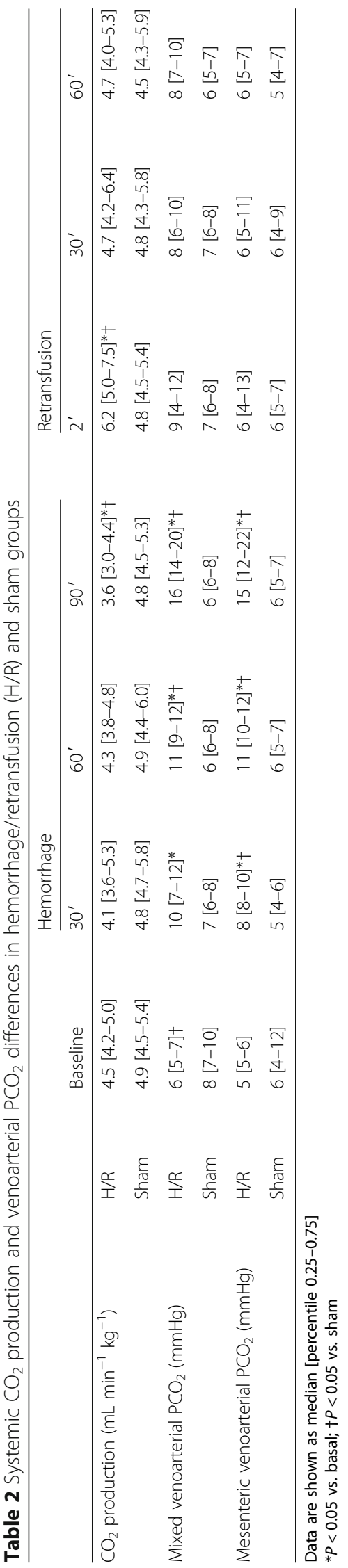



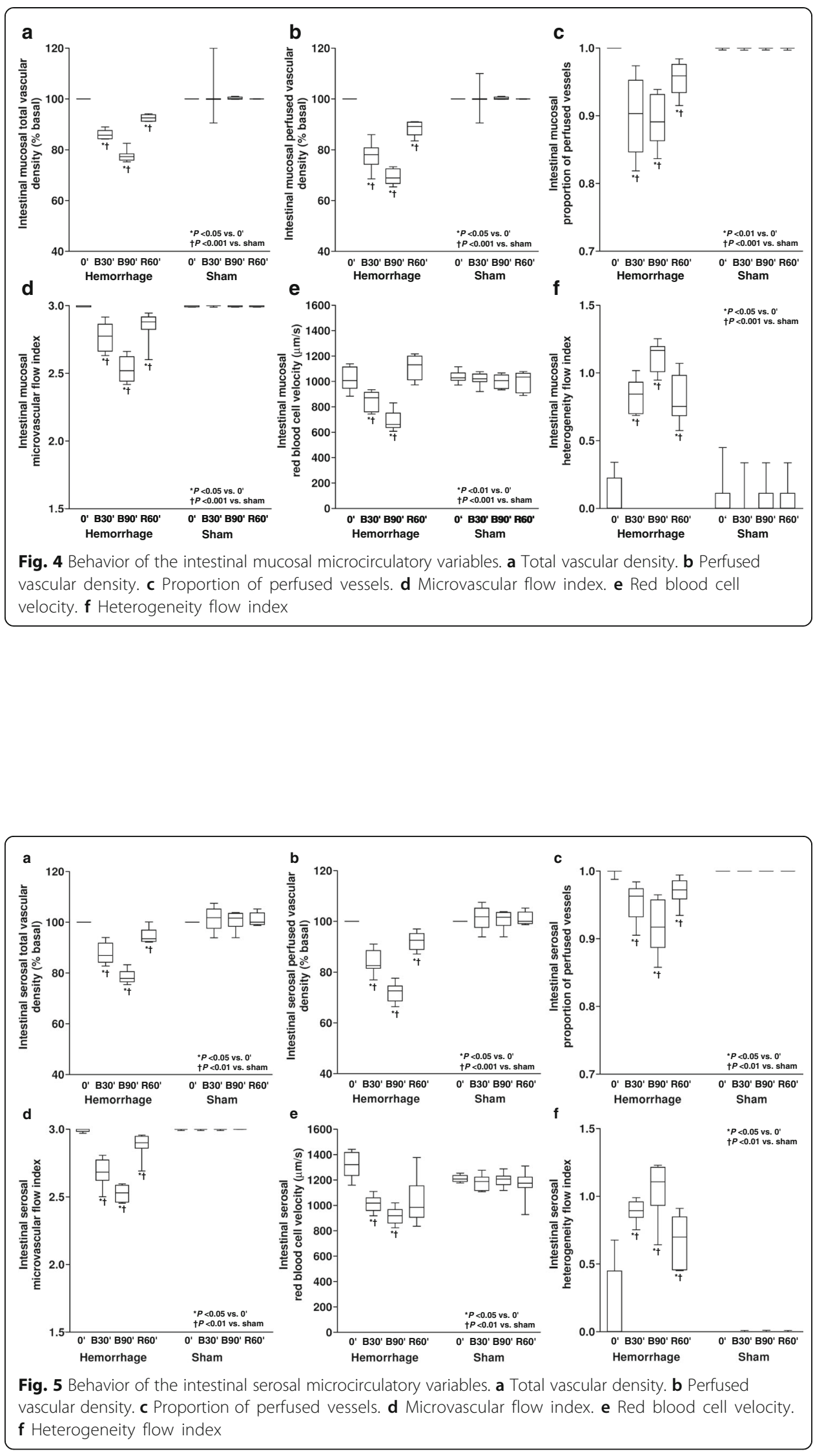


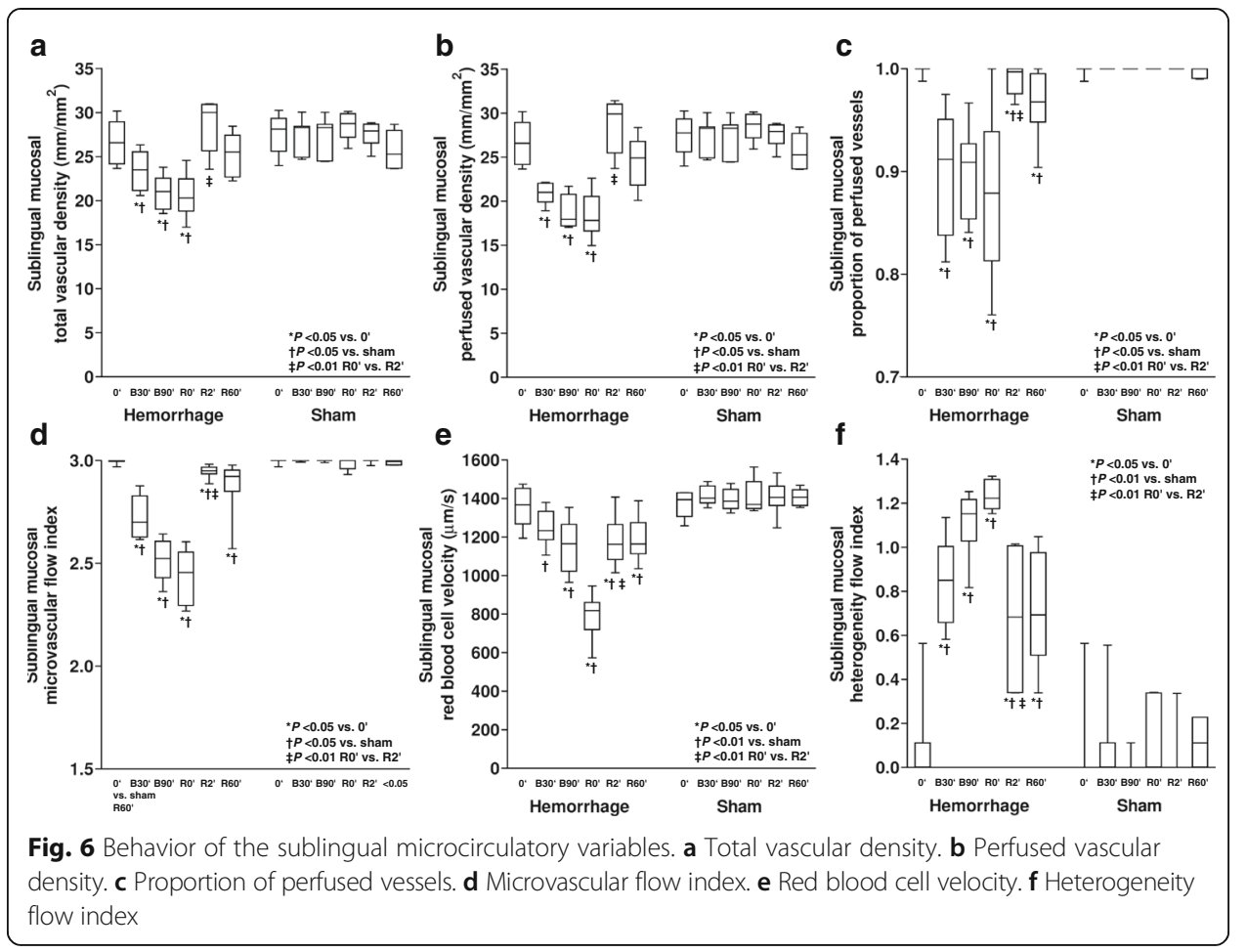

sublingual microvascular alterations in trauma patients might help to select patients who will benefit from blood transfusion. In patients with hemorrhagic shock, blood transfusion improved sublingual microcirculation independently of macrocirculation and hemoglobin level. The change in microvascular perfusion, however, was negatively correlated with the basal microvascular perfusion [28]. A similar response was described in trauma patients with hemodynamic stability [29]. The identification of microcirculatory disorders might thus contribute to the evaluation of patients with hemorrhagic shock.

Another original approach of this study was the continuous video acquisition in the sublingual area during retransfusion. This allowed a thorough assessment of the timing of capillary recruitment. While many microvascular parameters did not reach basal values, all microcirculatory variables improved sharply in the 2-min period of observation. In addition, the values at 2 ' were similar to those observed at the end of the reperfusion phase, evidencing that the changes in systemic hemodynamics rapidly recruited the microcirculation. Hence, we found a coherence between macro- and microcirculation, which was only partial, since most of the microvascular variables stayed altered.

The $\triangle \mathrm{PCO}_{2}$ is considered a sensitive marker of mucosal perfusion [22]. This study confirms the dependency of $\triangle \mathrm{PCO}_{2}$ on microcirculation. Nevertheless, $\triangle \mathrm{PCO}_{2}$ normalized at the end of the retransfusion period when microcirculatory alterations were still present. Consequently, our results suggest that tissue capnometry is less sensitive than videomicroscopy to disclose the presence of mucosal hypoperfusion.

Some studies have suggested that $\mathrm{P}_{\mathrm{v}-\mathrm{a}} \mathrm{CO}_{2} / \mathrm{C}_{\mathrm{a}-\mathrm{v}} \mathrm{O}_{2}$ could be an adequate surrogate for RQ $[9,10]$. Moreover, a cutoff of 1.4 might point out the presence of anaerobic metabolism. Nevertheless, $\mathrm{P}_{\mathrm{v}-\mathrm{a}} \mathrm{CO}_{2} / \mathrm{C}_{\mathrm{a}-\mathrm{v}} \mathrm{O}_{2}$ has never been compared to RQ. Our results 
showed that the correlation between both variables was weak, and more importantly, the physiological behavior was different. Given that RQ normalized after retransfusion, the increased $\mathrm{P}_{\mathrm{v}-\mathrm{a}} \mathrm{CO}_{2} / \mathrm{C}_{\mathrm{a}-\mathrm{v}} \mathrm{O}_{2}$ should be ascribed to increased release of $\mathrm{CO}_{2}$ from hemoglobin, not to tissue hypoxia. The persistent $\mathrm{P}_{\mathrm{v}-\mathrm{a}} \mathrm{CO}_{2} / \mathrm{C}_{\mathrm{a}-\mathrm{v}} \mathrm{O}_{2}$ elevation might result from changes in venous oxygen saturation (Haldane effect) and hemoglobin levels and mostly from persistent hyperlactatemia [30, 31]. All these factors can shift the $\mathrm{CO}_{2} \mathrm{Hb}$ dissociation curve. Since $\mathrm{P}_{\mathrm{v}-\mathrm{a}} \mathrm{CO}_{2} / \mathrm{C}_{\mathrm{a}-\mathrm{v}} \mathrm{O}_{2}$ might be a misleading indicator of RQ and anaerobic metabolism, its values should be carefully interpreted. This is additionally emphasized by the fact that ongoing anaerobic metabolism is identified by acute increases in RQ, not by isolated values [6-8]. Actually, the normal range of RQ is 0.67 to 1.30 [32].

Our study has some limitations. First, capillary reperfusion failure has been attributed to several mechanisms, including microthrombosis, leukocyte plugging, endothelial cell swelling, vasomotor dysfunction, and capillary narrowing due to edema [3]. Our study was only descriptive and did not address such mechanisms. In addition, we only studied three microvascular territories and the microcirculation might have behaved differently in other vascular beds. Finally, the assessment of retransfusion was limited to $60 \mathrm{~min}$. Longer observation periods might have produced different results.

\title{
Conclusions
}

Our main findings were that reperfusion microvascular injury developed in intestinal and sublingual areas, despite the complete restoration of aerobic metabolism. Since differences among microvascular beds were minor, sublingual mucosa might be an adequate window for the monitoring of intestinal reperfusion injury. Finally, given that $\mathrm{P}_{\mathrm{v}-\mathrm{a}} \mathrm{CO}_{2} / \mathrm{C}_{\mathrm{a}-\mathrm{v}} \mathrm{O}_{2}$ only had a poor correlation with $\mathrm{RQ}$ and a different physiologic behavior, it seems to be an inadequate surrogate for $\mathrm{RQ}$.

\section{Additional file}

Additional file 1: Video sublingual microcirculation during retransfusion. The video was continuously acquired during the period of shed blood reinfusion. Segments of the whole video were cut and edited. The left lower corner shows the actual time. There were sharp and fast increases in flow velocity and density. (WMV 13046 kb)

\begin{abstract}
Abbreviations
$\mathrm{C}_{\mathrm{a}-\mathrm{y}} \mathrm{O}_{2}$ : Arteriovenous oxygen content difference; $\mathrm{Cl}$ : Cardiac index; $\mathrm{DO}_{2}$ : Oxygen transport; H/R: Hemorrhagic shock and retransfusion; MFI: Microvascular flow index; $\mathrm{P}_{\mathrm{v}-\mathrm{a}} \mathrm{CO}_{2}$ : Venoarterial $\mathrm{PCO}_{2}$ difference; $\mathrm{P}_{\mathrm{v}-\mathrm{a}} \mathrm{CO}_{2} / \mathrm{C}_{\mathrm{a}-\mathrm{v}} \mathrm{O}_{2}$ : Ratio of venoarterial $\mathrm{PCO}_{2}$ to arteriovenous oxygen content difference; RBC: Red blood cell; RQ: Respiratory quotient; SDF: Sidestream dark field; SMABF: Superior mesenteric artery blood flow; $\mathrm{VCO}_{2}$ : Carbon dioxide production; $\mathrm{VO}_{2}$ : Oxygen consumption; $\triangle \mathrm{PCO}_{2}$ : Intramucosal-arterial $\mathrm{PCO}_{2}$
\end{abstract}

Acknowledgements

Data from this manuscript were presented at the ESICM Annual Congress in 2016

This work was performed in Facultad de Ciencias Médicas, Universidad Nacional de La Plata, Cátedra de Farmacología Aplicada, La Plata, Argentina.

Funding

This study was supported by the grant PICT 2010-00495, Agencia Nacional de Promoción Científica y Tecnológica, Argentina. 
Authors' contributions

GF, VSKE, HSC, EM, CC, GM, MOP, JFCE, MGB, and AD carried out the animal experiments and participated in the design of the study. AD performed the statistical analysis and drafted the manuscript. Cl participated in the study design and interpretation of the data. All authors discussed the results, participated in the writing, and approved the final the manuscript.

\section{Competing interests}

Dr Ince has developed SDF imaging and is listed as inventor on related patents commercialized by MicroVision Medical (MVM) under a license from the Academic Medical Center (AMC). He has been a consultant for MVM in the past, but has not been involved with this company for more than 5 years now, except that he still holds shares. Braedius Medical, a company owned by a relative of Dr Ince, has developed and designed a handheld microscope called CytoCam-IDF imaging. Dr Ince has no financial relation with Braedius Medical of any sort - i.e., he never owned shares or received consultancy or speaker fees from Braedius Medical. All other authors declare that they have no competing interests.

\section{Consent for publication}

Not applicable.

\section{Ethics approval}

The local research committee (Comité de Bioética y Ética de la Investigación) approved this study (reference number 0800-009634/11-000). Care of animals was in accordance with the National Institutes of Health (United States).

\section{Publisher's Note}

Springer Nature remains neutral with regard to jurisdictional claims in published maps and institutional affiliations.

\section{Author details}

${ }^{1}$ Cátedra de Farmacología Aplicada, Facultad de Ciencias Médicas, Universidad Nacional de La Plata, La Plata, Argentina. ${ }^{2}$ Translational Physiology, Academic Medical Center, University of Amsterdam, Amsterdam, Netherlands.

Received: 10 January 2017 Accepted: 12 April 2017

Published online: 21 April 2017

\section{References}

1. Crowell JW, Smith EE (1964) Oxygen deficit and irreversible hemorrhagic shock. Am J Physiol 206:313-316

2. Granger DN, Kvietys PR (2015) Reperfusion injury and reactive oxygen species: the evolution of a concept. Redox Biol 6:524-551

3. Menger MD, Rücker M, Vollmar B (1997) Capillary dysfunction in striated muscle ischemia/reperfusion: on the mechanisms of capillary "no-reflow". Shock 8:2-7

4. Nakajima Y, Baudry N, Duranteau J et al (2001) Microcirculation in intestinal villi: a comparison between hemorrhagic and endotoxin shock. Am J Respir Crit Care Med 164:1526-1530

5. Dubin A, Pozo MO, Ferrara G et al (2009) Systemic and microcirculatory responses to progressive hemorrhage. Intensive Care Med 35:556-564

6. Wasserman K, Whipp BJ, Koyl SN et al (1973) Anaerobic threshold and respiratory gas exchange during exercise. J Appl Physiol 35:236-243

7. Cohen IL, Sheikh FM, Perkins RJ et al (1995) Effect of hemorrhagic shock and reperfusion on the respiratory quotient in swine. Crit Care Med 23:545-552

8. Ferrara G, Kanoore Edul VS, Martins E et al (2016) Intestinal and sublingual microcirculation are more severely compromised in hemodilution than in hemorrhage. J Appl Physiol (1985) 120:1132-1140

9. Mekontso-Dessap A, Castelain V, Anguel $\mathrm{N}$ et al (2002) Combination of venoarterial $\mathrm{PCO}_{2}$ difference with arteriovenous $\mathrm{O}_{2}$ content difference to detect anaerobic metabolism in patients. Intensive Care Med 28:272-277

10. Monnet $\mathrm{X}$, Julien F, Ait-Hamou N et al (2013) Lactate and venoarterial carbon dioxide difference/arterial-venous oxygen difference ratio, but not central venous oxygen saturation, predict increase in oxygen consumption in fluid responders. Crit Care Med 41:1412-1420

11. Goedhart PT, Khalilzada M, Bezemer R et al (2007) Sidestream Dark Field (SDF) imaging: a novel stroboscopic LED ring-based imaging modality for clinical assessment of the microcirculation. Opt Express 15:15101-15104

12. Dobbe JG, Streekstra GJ, Atasever B et al (2008) Measurement of functional microcirculatory geometry and velocity distributions using automated image analysis. Med Biol Eng Comput 46:659-670

13. Pozo MO, Kanoore Edul VS, Ince C et al (2012) Comparison of different methods for the calculation of the microvascular flow index. Crit Care Res Pract 2012:102483

14. Trzeciak S, Dellinger RP, Parrillo JE et al (2007) Early microcirculatory perfusion derangements in patients with severe sepsis and septic shock: relationship to hemodynamics, oxygen transport, and survival. Ann Emerg Med 49:88-98

15. Ekman T, Risberg B, Soussi B et al (1993) Gastric mucosal microcirculation and purine nucleotide metabolism after retransfusion of rats in hemorrhagic shock. Scand J Gastroenterol 28:173-178

16. Cheung AT, Duong PL, Driessen B et al (2006) Systemic function, oxygenation and microvascular correlation during treatment of hemorrhagic shock with blood substitutes. Clin Hemorheol Microcirc 34:325-334

17. Cabrales P, Intaglietta M, Tsai AG (2007) Transfusion restores blood viscosity and reinstates microvascular conditions from hemorrhagic shock independent of oxygen carrying capacity. Resuscitation 75:124-134

18. Ortiz D, Barros M, Yan S et al (2014) Resuscitation from hemorrhagic shock using polymerized hemoglobin compared to blood. Am J Emerg Med 32:248-255

19. Paxian M, Keller SA, Huynh TT et al (2003) Perflubron emulsion improves hepatic microvascular integrity and mitochondrial redox state after hemorrhagic shock. Shock 20:449-457 
20. Scalia S, Burton H, Van Wylen D et al (1990) Persistent arteriolar constriction in microcirculation of the terminal ileum following moderate hemorrhagic hypovolemia and volume restoration. J Trauma 30:713-718

21. van Iterson M, Bezemer R, Heger M et al (2012) Microcirculation follows macrocirculation in heart and gut in the acute phase of hemorrhagic shock and isovolemic autologous whole blood resuscitation in pigs. Transfusion 52:1552-1559

22. Dubin A, Edul VS, Pozo MO et al (2008) Persistent villi hypoperfusion explains intramucosal acidosis in sheep endotoxemia. Crit Care Med 36:535-542

23. Boerma EC, van der Voort PH, Spronk PE et al (2007) Relationship between sublingual and intestinal microcirculatory perfusion in patients with abdominal sepsis. Crit Care Med 35:1055-1060

24. Edul VS, Ince C, Navarro $\mathrm{N}$ et al (2014) Dissociation between sublingual and gut microcirculation in the response to a fluid challenge in postoperative patients with abdominal sepsis. Ann Intensive Care 4(4):39

25. Szabó A, Vollmar B, Boros M et al (2006) Gender differences in ischemia-reperfusion-induced microcirculatory and epithelial dysfunctions in the small intestine. Life Sci 78:3058-3065

26. Tachon G, Harrois A, Tanaka S et al (2014) Microcirculatory alterations in traumatic hemorrhagic shock. Crit Care Med 42:1433-1441

27. Ward KR (2013) The microcirculation: linking trauma and coagulopathy. Transfusion 53(Suppl 1):38S-47S

28. Tanaka S, Escudier E, Hamada S et al (2017) Effect of RBC transfusion on sublingual microcirculation in hemorrhagic shock patients: a pilot study. Crit Care Med 45:e154-e160

29. Weinberg JA, MacLennan PA, Vandromme-Cusick MJ et al (2012) Microvascular response to red blood cell transfusion in trauma patients. Shock 37:276-281

30. Hachamovitch $\mathrm{R}$, Brown HV, Rubin SA (1991) Respiratory and circulatory analysis of $\mathrm{CO}_{2}$ output during exercise in chronic heart failure. Circulation 84:605-612

31. Sun $X G$, Hansen JE, Stringer WW et al (2001) Carbon dioxide pressure-concentration relationship in arterial and mixed venous blood during exercise. J Appl Physiol (1985) 90:1798-1810

32. McClave SA, Lowen CC, Kleber MJ et al (2003) Clinical use of the respiratory quotient obtained from indirect calorimetry. JPEN J Parenter Enteral Nutr 27:21-26

\section{Submit your manuscript to a SpringerOpen ${ }^{\circ}$} journal and benefit from:

- Convenient online submission

- Rigorous peer review

- Immediate publication on acceptance

- Open access: articles freely available online

- High visibility within the field

- Retaining the copyright to your article 